\title{
Design and Construction of the NSTX Bakeout, Cooling and Vacuum Systems
}

\author{
L. E. Dudek, W. Blanchard, M. Kalish, R. Gernhardt and R. F. Parsells \\ Princeton University Plasma Physics Laboratory \\ P.O. Box 451 \\ Princeton, N.J. 08543
}

\begin{abstract}
This paper will describe the design, construction and initial operation of the NSTX bakeout, water cooling and vacuum systems.

The bakeout system is designed for two modes of operation. The first mode allows heating of the first wall components to $350{ }^{\circ} \mathrm{C}$ while the external vessel is cooled to $150^{\circ} \mathrm{C}$. The second mode cools the first wall to $150{ }^{\circ} \mathrm{C}$ and the external vessel to $50{ }^{\circ} \mathrm{C}$. The system uses a low viscosity heat transfer oil which is capable of high temperature low pressure operation.
\end{abstract}

The NSTX Torus Vacuum Pumping System (TVPS) is designed to achieve a base pressure of approximately $1 \times 10^{-8}$ Torr and to evacuate the plasma fuel gas loads in less than 5 minutes between discharges. The vacuum pumping system is capable of a pumping speed of approximately $3400 \mathrm{l} / \mathrm{s}$ for deuterium. The hardware consists of two turbo molecular pumps (TMPs) and a mechanical pump set consisting of a mechanical and a Roots blower pump. A PLC is used as the control system to provide remote monitoring, control and software interlock capability.

The NSTX cooling water provides chilled, de ionized water for heat removal in the TF, $\mathrm{OH}$ and $\mathrm{PF}$, power supplies, bus bar systems, and various diagnostics. The system provides flow monitoring via a PLC to prevent damage due to loss of flow.

\section{INTRODUCTION}

The National Spherical Torus Experiment (NSTX) was designed and sited at the Princeton Plasma Physics lab. The extensive array of existing auxiliary equipment left behind by the shutdown of TFTR allowed many resource-saving opportunities. One of the design requirements for the NSTX auxiliary systems was to use as much of the existing equipment as practical.

\section{TORUS VACUUM PUMPING SYSTEM}

The NSTX Torus Vacuum Pumping System (TVPS) consists of the following:

1) A portable mechanical pump for roughdown;

2) A separate pumping system for achieving and maintaining high vacuum;

3) Associated valves, gauges, and analytical instrumentation necessary to operate the system.

All of this equipment was obtained from the TFTR spares inventory. The TMPs are mounted off a 24-inch diameter pumping duct connected to the vacuum vessel at the midplane. A bellows and ceramic break are provided to allow for thermal expansion during bakeout and to electrically isolate TVPS from the vacuum vessel Both of these items were also obtained from TFTR spares. The length of the pumping duct was kept short ( 14 feet) in order to maximize conductance. The backing systems is located on a skid on the test cell floor adjacent to the pump duct. In order to avoid venting gasses within the building, an exhaust line is routed from the mechanical pump to the plant stack.

The roughing system consists of a portable pump system incorporating a mechanical pump and a blower pump.

This system takes about two hours to pump the vacuum vessel (approximately 30,000 liters) from atmospheric pressure to $40 \mathrm{mTorr}$ at which point the high vacuum system is employed. The roughing system is disconnected when not in use.

\section{A. Component Design Features}

The high vacuum system consists of a pair of 30001/s TMPs. The TMPs are vertical axis, oil lubricated, multi-stage pumps which are isolated from the pumping duct by 16 -inch gate valves. These pumps evacuate the torus to high vacuum via a single 24 -inch diameter pumping duct. The TMPs are backed by a pump set that consists of a positive displacement lobe type Roots blower with a rotary piston mechanical pump. Both pumps are mounted on a common base. The mechanical pump has an approximate pumping speed of 100 CFM and the blower approximately 800 CFM. This pump set also provides sufficient pumping speed for maintaining the foreline at an adequate pressure during glow discharge cleaning (GDC) operations when the torus is maintained at 2-4 mTorr with both TMPs pumping on the vacuum vessel. The vacuum system is controlled and monitored from a programmable logic controller (PLC) using a PC user interface. The TMPs are monitored for water flow, , vibration, temperature and oil level while the backing pump set is monitored for water, oil, temperature and pump speed. Interlocks to provide equipment safety are programmed into the operating system logic and the system is automatically configured into a safe configuration on the loss of a permissive. The PLC provides remote control of valves and pumps to accomplish startup, operation and safe shutdown and is interlocked to prevent misoperation of the system. Additional control signals are routed to the main (control room) computer for display and control of system status through the site network. The TFTR liquid nitrogen system provides dry nitrogen at approximately 6 psig to vent pumps and piping. 


\section{B. Instrumentation}

Bayard-Alpert ionization gauges are used for high vacuum (lower than $10^{-3}$ torr) measurements. These gauges are monitored and controlled remotely via the PLC. They are also interfaced to the main computer to provide feedback control of the gas injection assemblies on NSTX.

There are numerous capacitance manometers $(\mathrm{CMs})$ on the vacuum vessel and TVPS measuring pressures between atmosphere and the mTorr range. Besides measuring the vacuum integrity of the forelines they are also used for the measurement and feedback control of gas feed during GDC. All of the CMs are monitored and interlocked by the PLC.

Two RGA systems are employed for diagnostic and trending purposes. The RGA system is able to scan and provide resolution of $1 \times 10^{-11}$ torr partial pressure for masses 1 to 100 . Local and remote readout and control of the RGA is provided.

\section{System Performance and Initial Operation}

The performance of the TVPS on NSTX has been very good. The reliability and versatility of the system has been excellent. Since startup of TVPS in November of 1998, the system has operated with no lost down time during three pumpdowns, more than 100 hours of GDC and plasma operations. The system has maintained the vacuum vessel in the 10-8 Torr range with only a minimal bakeout of the torus. It is expected that when the internal surfaces of NSTX are thoroughly baked out, $1 \times 10-8$ Torr should be readily achieved-

\section{NSTX COOLING WATER SYSTEM}

The NSTX Cooling Water System combines new design with the extensive use of existing TFTR equipment to provide cooling water to coils, busswork, and various components.

A 33,000-gallon storage tank is polished by a deionized water-polishing loop maintaining high resistivity. This tank is maintained with a nitrogen blanket at a pressure of $40 \mathrm{psig}$. The primary circulating pump for NSTX is a $100 \mathrm{hp}$ centrifugal pump capable of providing $600 \mathrm{gpm}$ at $150 \mathrm{psig}$. The installation takes advantage of existing piping in the D-site pump room. An existing 400-ton flat plate heat exchanger provides the heat sink to the system. Using this heat exchanger the deionized water can be chilled with the HVAC chilled water supply. The deionized water can also be cooled directly by a 1100 ton process chiller. All of this equipment was originally used to cool the TFTR coil system.

A bypass control valve in the pump room is used to maintain constant pressure to NSTX. New automatic valves on the main supply and return to the NSTX test cell provide the ability to remotely cut off the water supply from the control room if required. Instrumentation on the supply line to NSTX in the test cell indicates pressure, temperature, and water resistivity. Dew point is monitored and compared to inlet water temperature. If water temperature drops below dew point the water system PLC will trip the cooling system to prevent the occurrence of a busswork arc-over induced by water condensation. High-pressure water is provided to the $\mathrm{OH}$ coils by a small $7.5 \mathrm{hp}$ centrifugal booster pump. A second booster pump with potable water as an alternate supply of cooling provides emergency backup. Taps in the supply and return headers provide for busswork, diagnostics and various other components requiring cooling. Taps off of the supply header include valves to provide isolation for each cooling path. Flexible hoses bring the water from the taps off of the supply header to the individual coils. For coil protection, flow instrumentation is provided on the return side of each individual coil flow path. The coil path flow venturis measure flow in the range of 0.5 to 4.5 GPM and provide a switched output to the PLC. These water flow switches and analog temperature switches furnish signals to the PLC which process the data and provide an enable signal for the next pulse.

All of the existing equipment, primary pump, bypass pressure control, storage tank, deionized water polishing loop, and heat exchanger, are located in the "D Site Pump Room". The primary pump is at an elevation $33 \mathrm{ft}$ below the midplane of NSTX. Water is provide from the D site pump room through 4" supply and return lines approximately $200 \mathrm{ft}$ long into the NSTX Test Cell. The return and supply skids are located just south and south east of the vacuum vessel. Hoses run from the supply skid to the various coil cooling water inlet connections and back from the coil outlet connections to the return skid. Access to valves and hoses are maintained to allow for troubleshooting and maintenance. To minimize piping runs the booster pumps are mounted in the NSTX test cell. Sound insulation is provided on the high pressure pumps to attenuate the noise.

The deionized water polishing loop utilizes a cation, anion, mixed bed, and carbon filter maintaining resistivity at about $2 \mathrm{mega} \mathrm{ohm} \mathrm{cm}$. In addition to the beds, the polishing loop consists of pump, flow meter, filters, and resistivity meters.

\section{A. Instrumentation}

A Gould PLC, used for TFTR water systems, was re-used for NSTX. A satellite PLC cabinet is located in the NSTX test cell and interfaced with the PLC in the D site pump room via a fiber optic cable. The PLC monitors valve positions, system pressures, temperatures, dew point, tank level, pump status, and coil flow. The PLC provides a signal to the NSTX interlock system that will inhibit the pulse permissive if system parameters are not met. Remote pump starts and valve actuation are available from the PLC through central I\&C. The PLC will automatically shut pumps and valves to place the system in a safe state if system parameters indicate abnormal conditions. 


\section{B. System Operations}

The existing equipment, primary pumps and heat exchanger alignment, are controlled locally in the D Site Pump Room. To avoid pressure surges and insure smooth operation this equipment is started up before opening the NSTX inlet and return AV valves.

After pressure has stabilized in the supply headers the AV valves are opened and indication of sufficient flow for each flow path is noted.

The $\mathrm{OH}$ booster pump is then started and flow verified to the $\mathrm{OH}$ coils. After return header pressure, temperatures and water resistivity are verified within acceptable limits machine operations may begin.

\section{NSTX TORUS BAKEOUT SYSTEM}

The NSTX Torus Bakeout System (TBS) consists of the following design elements:

1) An internal heating coil system circulating high temperature heat transfer fluid provides the means to heat the protective plate carbon tiles to the required $350^{\circ} \mathrm{C}$ bakeout temperature.

2) An external heating / cooling coil system circulation high temperature heat transfer fluid provides the means to heat / cool the vacuum vessel surfaces to the required $150^{\circ} \mathrm{C}$.

\section{A. Design Features}

Each of these elements includes all the equipment and hardware to perform these design functions as well as the associated valves, gauges, and analytical instrumentation necessary to operate these systems. The internal tile bakeout system consists of $1 / 2$ " diameter stainless steel heating coils mounted on the back side of the plasma facing components (PFC). The external vacuum vessel bakeout system consists of $1 / 2$ " diameter stainless steel heating / cooling coils. These coils are mounted on the vacuum vessel external surfaces. Temperature instrumentation for the bakeout system is provided by several instruments. Type $\mathrm{J}$ thermocouples provide temperature indication for the vacuum vessel shell. Temperature controllers monitor thermocouple input and are used to maintain $150^{\circ} \mathrm{C}$ for the vacuum vessel.

The TBS is mounted on a vendor supplied system skid located in the NSTX test cell. The internal heating coils are mounted on the back side of the PFC at a nominal spacing of 4 inches. The external heating / cooling tubes are located on the vacuum vessel surface at a nominal spacing of 4 inches.

The Center stack is ohmically heated by passing low voltage current through the inconel casing. This supplements the interior vacuum vessel heating of PFC. This system is rated at $20 \mathrm{~kW}$ using $5.8 \mathrm{kA}$ steady state.

The equipment on the TBS skid consists of electric circulation heaters, two pumps one for each low and high temperature system, an expansion tank and the related control and monitoring equipment. The circulation heaters are incoloy sheathed heating elements for heating liquids remote from the tank. Each heater is rated at $40 \mathrm{~kW}$. The elements are flange mounted on a 8 " diameter flanged pipe, nominally 5 feet long. The process heater controls are, digital readout, solid state micro processor based fully selectable range control.

The circulation pumps are high temperature insulated designs, suitable for handling high temperature fluids, 1 x 1-1/2 canned motor pumps. The chilled water /heating liquid heat exchanger is a flat plate heat exchanger. The unit is rated at $12 \mathrm{~kW}$ per $10 \mathrm{gpm}$ chilled water flow \& $10^{\circ} \mathrm{F}$ delta $\mathrm{T}$. The heating liquid expansion tank is insulated and vented.

Each of the heating/cooling loops has a thermocouple and a control valve to control temperature and flow.

\section{B. System Operation}

Operation of the TBS from ambient temperature to bakeout temperature and return to normal operating temperature is as follows:

1) The heating liquid system is enabled and started to heat the PFC. The center stack ohmic heating system is started to bring the center stack tiles to $350^{\circ} \mathrm{C}$.

2) The chilled water heat exchanger is enabled and operates to cool the VV while the PFC are heated.

3) The internal heating system continues to supply heat energy until the PFC. reach $350{ }^{\circ} \mathrm{C}$. At this point the system is modulated to maintain $350^{\circ} \mathrm{C}$ and then shut down.

4) The external cooling system continues to operate until the system is returned to normal operating temperature.

The NSTX TBS was installed in the summer of 1999. As part of the safety review performed prior to startup a fire engineering consultant was hired to perform a safety review of the system. The heat transfer fluid used in the design has a flash point of approximately $113^{\circ} \mathrm{C}$. Since the system operates above this temperature several design issues were raised. Among these recommendations were the addition of a mist type sprinkler system, early fire detection system and relocation of the skid from inside the building to outside the building. Operation of the bakeout skid has been suspended pending evaluation of these recommendations.

\section{CONCLUSION}

With the successful completion and startup of the NSTX auxilliary systems it has been demonstrated that significant cost and time savings can be realized by reusing systems from TFTR.

\section{ACKNOWLEDGMENT}

This work was supported by U.S. DoE Contract No. DE-AC02-76CH03073. 


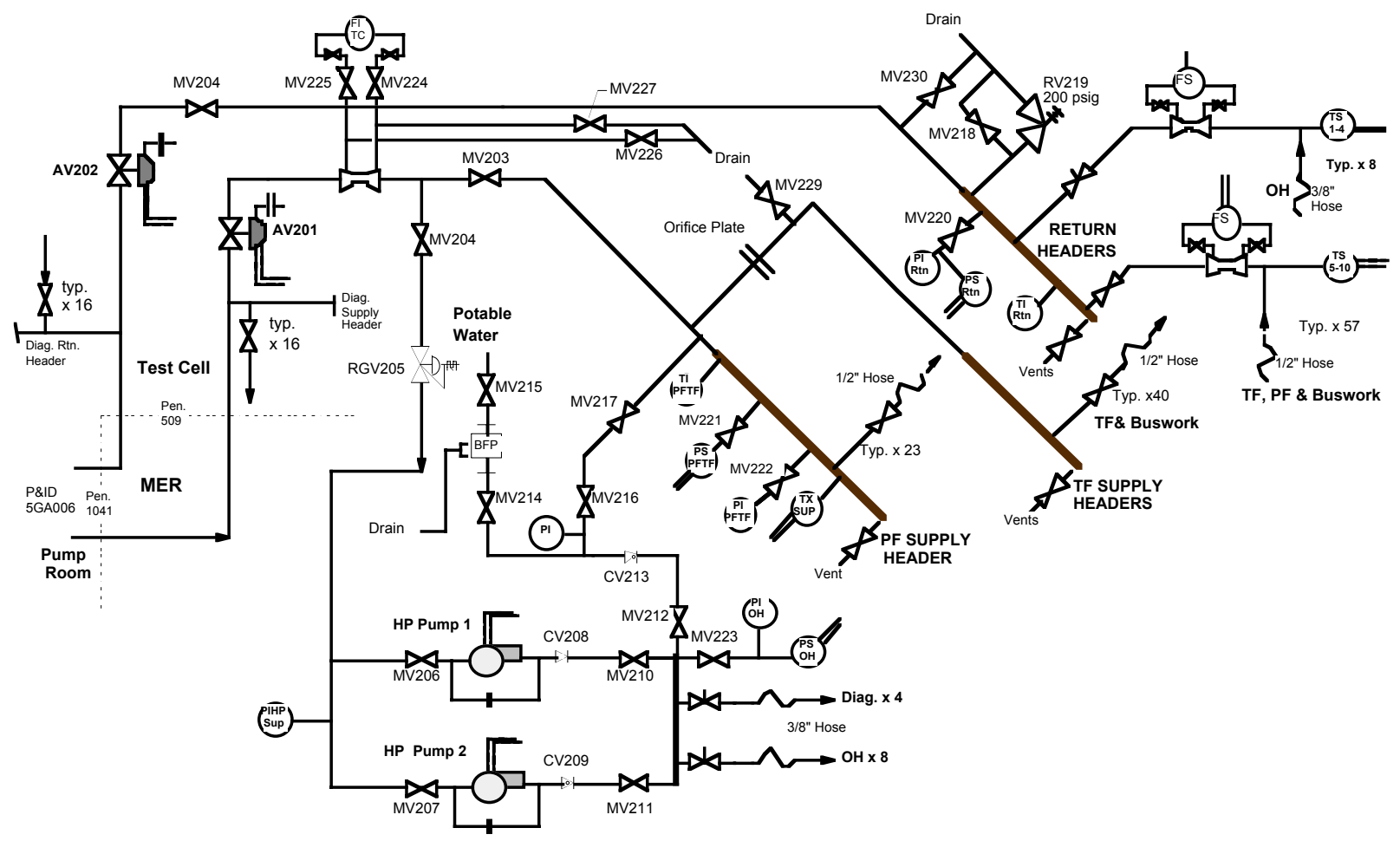

Figure 1: NSTX Water System Flow Diagram

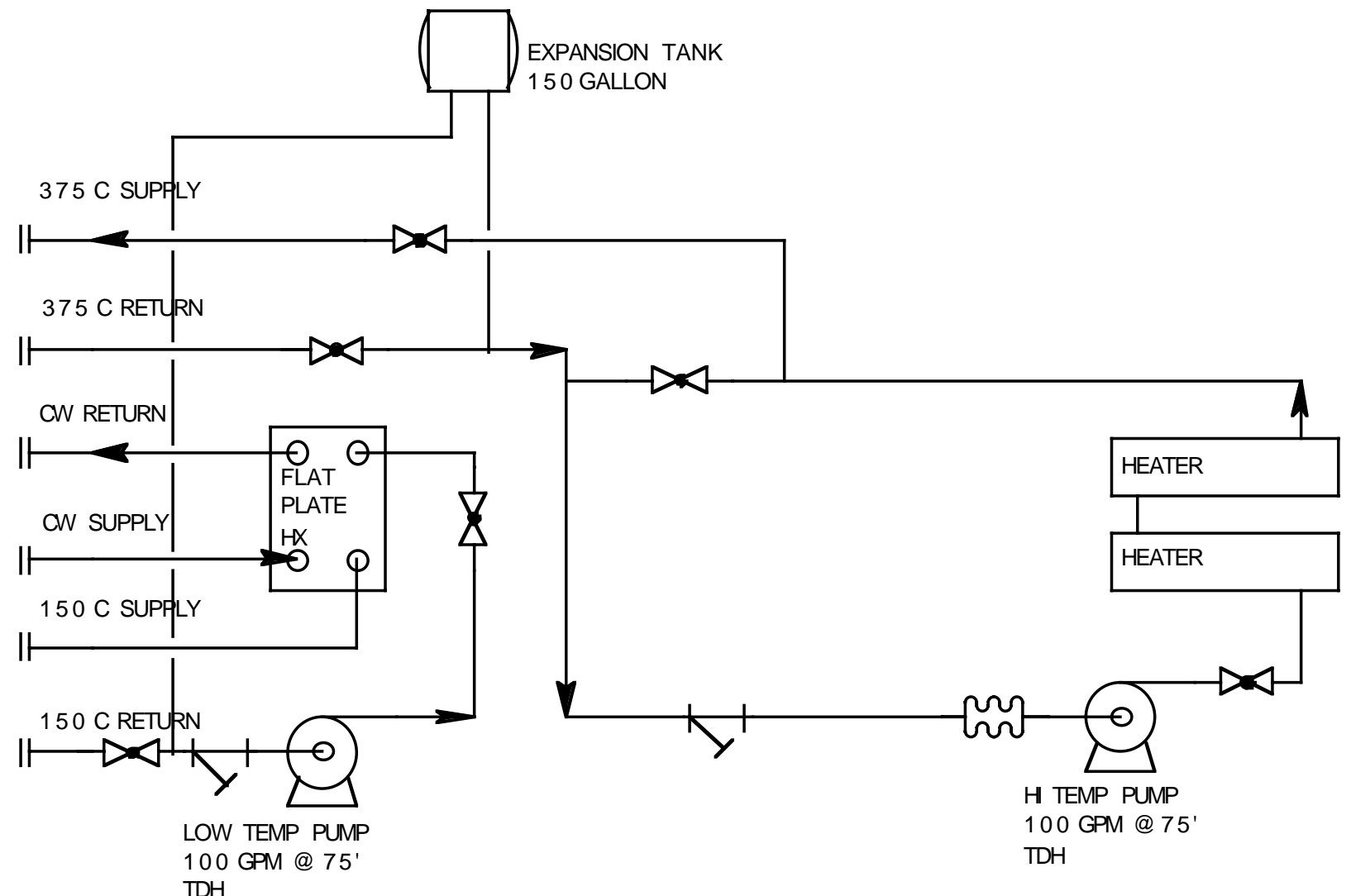

Figure 2: NSTX TBS Block Diagram 